\title{
Note on a demonstration-differential thermometer
}

\section{Henri Dufour}

To cite this article: Henri Dufour (1880) Note on a demonstration-differential thermometer, Philosophical Magazine Series 5, 10:60, 143-144, DOI: 10.1080/14786448008626909

To link to this article: http://dx.doi.org/10.1080/14786448008626909

曲 Published online: 28 Apr 2009.

Submit your article to this journal $\pi$

Џll Article views: 2

Q View related articles $\sqsubset$ 
These results show that the vapour-density of iodine, calculated with $\alpha=0.00367$ and $P V=1$, diminishes quite as much at a low as at a high temperature.

All the hypotheses which have been framed on the assumption of either a dissociation of, or isomeric change in, iodine henceforth appear to me hardly admissible. In the present state of our knowledge, nothing authorizes us to suppose that a partial vacuum would be adequate to produce a modification of that nature. The only necessary consequences of the experiments made at high temperatures or at low pressures are, that the expansion-coefficient of iodine varies with the temperature, and that its coefficient of compressibility varies with the pressure. Every hypothesis proposed in order to explain these results will have to take into account this double variation.-Comptes Rendus de l'Académie des Sciences, July 5, 1880 , t. xci. pp. 54-56.

\section{NOTE ON A DEMONSTRATION-DIFFERENTIAL THERMOMETER. BY HENRI DUFOUR.}

For the purpose of exhibiting, in lectures on physics, the principal phenomena due to the radiation of heat, the thermoelectric pile and a galvanometer are usually employed. If the latter is a reflecting one (such as that of M. Wiedemann), it is easy to render visible to a numerous auditory some of the most delicate thermal phenomena. The only inconvenience of these two instruments is their high price; perhaps it is on account of this that the study of the radiation of heat is so often neglected in colleges which possess but slender resources. It is in order to render the study of these phenomena possible to every one, that I have constructed the following instrument, which can be easily executed anywhere at a very moderate price.

A tube in the shape of a very widely open $V$ (the two branches making an angle of about $140^{\circ}$ ) is terminated at one of its ends by a blackened bulb. A horizontal lever of very light wood unites the two brancbes as the bar of an inverted $A(v)$ would do ; this lever turns on a horizontal axis fixed to the middle of its length; upon the axis is a vertical needle, which moves in front of a graduated dial, likewise vertical.

A short column of mercury is introduced into the tube so that it occupies its lower portion. Equilibrium being established, the indicating needle is at the zero of the graduation. Under these conditions any heating of the bulb produces expansion of the air which it contains, and consequently a displacement of the mercury index, under the influence of which the apparatus inclines more or less; it afterwards returns to zero when the action of the source of heat ceases to operate.

To regulate the horizontality of the beam, a small brass cursor can be placed on the lever at a variable distance from the axis. Lastly, the motion of the apparatus is very regular if the precaution 
be taken of introducing into the tube containing the mercury a small quantity of concentrated sulphuric acid to protect the terminal surfaces of the mercury from oxidation.

In order to employ this apparatus for the study of the phenomena of radiant heat, a polished brass cone is placed inside at a short distance from the bulb, the diathermanous substances to be investigated being fixed between the small aperture of the cone and the bulb; the heat of a wax taper, sent back by a small rellector, suffices for most experiments. The absorptive and emissive powers of the various substances are easily studied by preparing a certain number of small disks of copper (such as the circular copper plates of a Volta pile); each disk is coated on one side with lampblack, on the other with the substance whose absorbing-power is to be determined. All the disks being heated together in a metal vessel, we have only to place them successively at the same distance from the bulb, the substance to be studied facing the bulb, in order to determine the emissive powers.

If the same disks bo placed all at the same distance from a stove or any source of beat, the different faces being turned towards the source of heat, and be then placed successively each with its black face looking towards the bulb, the inequality of their absorbingpowers is shown by the inequality of the deflections of the instrument.

As will be seen, the instrument is nothing else but a differential bulb-thermometer; but its indications are more easily read at a distance than those of Rumford's or Leslie's apparatus. Of course, as the apparatus varies with the barometric pressure and the temperature of the surrounding medium, the horizontality of the lever must be established, by shifting the cursor, before commencing a series of experiments.

This apparatus may be made of very various dimensions. That which I use has its lever about 14 centims. in length, the mercury index 5 centims. I have constructed another much smaller, of only 3 centims. length, the bulb of which has a diameter of only about 5 millims., and the tube is almost capillary. With the instrument it is very easy to verify the distribution of the heat in the solar spectrum. It can also be constructed with two bulbs, like the ordinary differential thermometer; but it is then less sensitive*.-Bibliotheque Universelle, Archives des Sciences Physiques et Naturelles, tome iv. no. 7, pp. 71-73.

* At the time I constructed the above-described instrument I knew nothing about M. Marey's thermograph (see Méthode graphique dans les sciences expérimentales, par M. E.-J. Marey, p. 314). This appears to me more difficult to construct than that which I propose; but it has the advantage of possessing a fixed bulb. 